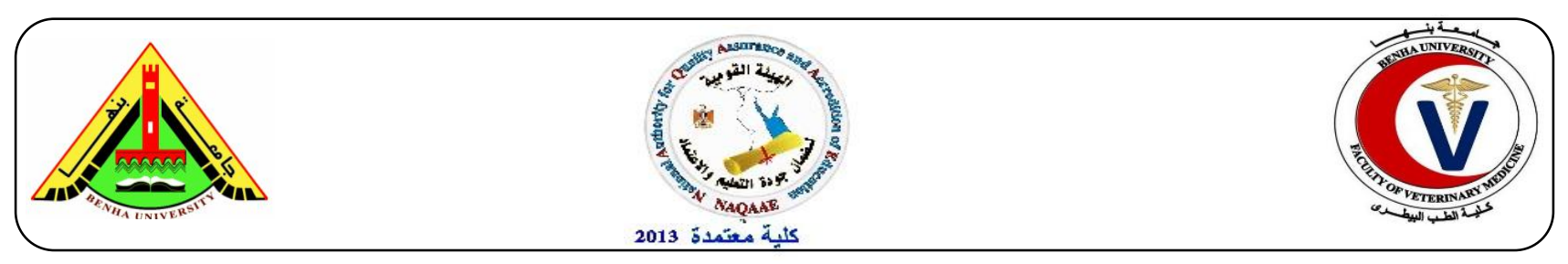

\title{
Hepatoprotective Effect of Allopurinol and Garlic Extract against Experimentally - Induced Hepatotoxicity
}

\author{
Aya M. Amer, Ayman S. Farid, Khalid M. Fararah \\ Dept. of Clinical Pathology, Faculty of Vet. Med., Benha University, Egypt.
}

\section{A B S T R A C T}

The present study was designed to investigate the hepatoprotective and antioxidant effects of allopurinol and garlic extract against acetaminophen and ethanol induced hepatotoxicity and oxidative stress in rats. Animals were divided into four groups .Group 1 was used as a control. Group2 was administered paracetamol plus ethanol orally for 14 days beginning from day $15-28$ of the experiment. Group 3 was administered allopurinol orally for 28 days, and from day $15-28$ of the experiment rats were given paracetamol plus ethanol orally till the end of the experiment. Group 4 was administered garlic extract orally for 28 days, and from day 15- 28 of experiment rats given paracetamol orally plus ethanol till the end of the experiment. Serum was separated and used directly for determination of alanine aminotransferase(ALT), aspartate aminotransferase(AST), albumin, alkaline phosphatase(ALP), bilirubin(BIL) and Tumor necrosis factor -alfa(TNF).Liver samples were taken for histopathological examination, liver malondiadehyde(MDA), Glutathione peroxidase(GPX)and nitric oxide(NO).The result revealed that in group 2 there were significant elevations of alanine aminotransferase, aspartate aminotransferase, alkaline phosphatase, bilirubin, Tumor necrosis factor-alfa and liver malondiadehyde and nitricoxide. Furthermore, there were significant decreases in Glutathione peroxidase and albumin compared with control group. Meanwhile, administration of Allopurinol and garlic resulted in significant decrease in all elevated mentioned parameter and increase in Glutathione peroxidase and albumin compared with hepatotoxicity group. Therefore it could be concluded that allopurinol and garlic as strong hepatoprotective and antioxidant effects

Key words: Paractamol- garlic extract - allopurinol - hepatoprotection.

http://www.bvmj.bu.edu.eg)

(BVMJ-34(2): 66-76, 2018)

\section{INTRODUCTION}

Liver diseases remain one of the serious health problems throughout the world associated with a high rate of morbidity and mortality (Pushpavalli et al., 2010). Overdose of acetaminophen can cause potentially fatal liver damage, and its toxicity is the foremost cause of liver failure in western world (Daly 
Hepatoprotective effect of allopurinol and garlic extract against experimentally - induced hepatotoxicity

et al.,2008). Acetaminophen is activated and converted by cytochrome P450 enzymes to toxic metabolite NAPQI ( $N$-acetyl- $p$ benzoquinoneimine) that causes oxidative stress and glutathione (GSH) depletion which is associated with its hepatotoxicity (Hinson et al., 2010).Previous reports claiming that the hepatotoxicity of acetaminophen is increased in chronic alcoholics, and that individuals carry an increased risk of severe and fatal liver damage after acute over dosage (Laurie,2016). On the other hand, allopurinol has a well-known action in the blockade of xanthine oxidase (XO) enzyme, and it has a cytoprotective potential against injury provoked by reoxygenation. Since Kupffer cells contain $\mathrm{XO}$, which is one potential source of free radicals, allopurinol has been suggested to ameliorate hepatic injury by inhibition of $\mathrm{XO}$ and reduction of oxidative stress (Basimet al., 2015).Natural herbals plays significant roles in the prevention and treatment of many organic and inflammatory diseases associated with oxidative stress (Wariset al., 2006). Polyphenols and flavonoids that are present in plant-derived products are widely reported to exert significant influences on the removal of reactive oxygen and nitrogen species and have been useful in such diseases as diabetes mellitus and arthrosclerosis (Dugan et al ., 2005).Garlic has antioxidant, anti-thrombotic, hypo-cholesterolemic and anti-hypertensive properties. The bulb of the plant has been used as a carminative, anti-septic, expectorant, anti-helminthic (El-Khishin et al., 2015).Therefore the aim of the present study was to investigate the hepatoprotective effect of allopurinol and garlic extract against acetaminophen and ethanol induced hepatotoxicity in rats through evaluation of hematological, biochemical, antioxidant, antiinflammatory and histopathological changes in liver tissue.

\section{MATERIALS AND METHODS}

\subsection{Animals:}

Male Wistar rats weighting about 180 -200 gm obtained from the animal house of faculty of Veterinary Medicine, Benha University, Egypt were used in this study. All animals were caged and maintained on a standard powder diet with free access to tap water and were acclimatized for 1 week before starting the experiments. Animals were weighted weekly to adjust the dosage of chemicals.

\subsection{Chemical experimental substances:}

Paracetamol as $\mathrm{Cetal}^{\circledR}$ containing $250 \mathrm{mg}$ paracetamol $/ 5 \mathrm{ml}$ was obtained from Egyptian International Pharmaceutical Industries Company (EIPICO), Egypt.

Ethanol as (Ethyle Alcholol) was obtained from El Nasr Company, Egypt.

Allopurinol as Zyloric ${ }^{\circledR} 100 \mathrm{mg}$ Tablets was obtained from ASPN company

Garlic Extract was Prepared and stored at $-20{ }^{\circ} \mathrm{C}$ until being used according to method of Eidi et al. (2006).

\subsection{Expermintal design:}

In this study, 40 adult male Wistar rats were divided into four equal groups as follow: Group1 (Control group): served as control, rats received distilled water orally for 28 days. Group 2 (Hepatotoxicity group): received $0.5 \mathrm{gm} / \mathrm{kg} /$ day paracetamol plus ethanol $1 \mathrm{gm} / \mathrm{kg} /$ day orally for 14 days from day $15-28$ of the experiment Group 3(Allopurinol protected group): received 50 $\mathrm{mg} / \mathrm{kg}$ /day allopurinol orally for 28 days and from day $15-28$ of the experiment, rats were given $0.5 \mathrm{gm} / \mathrm{kg} /$ day paracetamol plus ethanol $1 \mathrm{gm} / \mathrm{kg} /$ day orally . Group 4 (Garlic protected group): received $500 \mathrm{mg} / \mathrm{kg} /$ day garlic extract orally for 28 days and from day 15 - 28 of experiment, rats given 0.5 gm 
$/ \mathrm{kg} /$ day paracetamol orally plus ethanol $1 \mathrm{gm} / \mathrm{kg} /$ day .

\subsection{Sampling:}

Blood samples were collected at end of third and fourth weeks from retro-orbital venous plexus for separation of serum to be used in estimation of biochemical parameters. Serum samples were used for quantitative determination of ALT, AST, albumin, ALP, total bilirubin, direct bilirubin and TNF- $\alpha$.

Liver tissue specimens: At the end of the third and fourth week rats were sacrificed by cervical decapitation. The liver specimens were quickly removed, then washed with cold saline to exclude the blood cells, and then blotted on filter paper. The liver was divided into two parts. The first part (1gm) was suspended in $4 \mathrm{ml}$ physiological saline $(0.9 \%$ Nacl) for homogenization (Teflon Homogenizer, india). The tissue homogenate were centrifuge $1500 \mathrm{xg}$ for $20 \mathrm{~min}$ at $4^{\circ} \mathrm{CThe}$ supernatants were kept at $-20^{\circ} \mathrm{C}$ till the time of determination of oxidative/antioxidative parameters (Yuan et al., 2010). The second part was placed in $10 \%$ formalin solution for histopathological investigation.

2.5.Biochemical parameter measurement:

Malondialdhyde was determined by the reaction described by Kei (1978) and Ohkan'a et al. (1979)Glutathione peroxidase was determined according to the method described by Paglia and Valentine (1967).Nitric oxide concentration was determined according to the method described by Montgomery et al. (1961).TNF$\alpha$ was determined by sandwish enzyme linked immune sorbent assay technology (ELISA) described by Visentainer et al.(2003).Kinetic determination of ALT and AST activities was performed according to Reitman and Frankel. (1957).Colorimetric determination of albumin was performed according to the method of Doumna et al. (1972)Total and direct bilirubin was determined spectroFig.metrically according to Burtis et al. (2012).Colorimetric determination of ALP activity was performed according to the method of Tietz et al. (1983).

\subsection{Statistical analysis:}

Data obtained were statistically evaluated for the mean and stander error (S.E). Statistical analysis was performed with statistical package for the social science (SPSS) software. $p<0.05$ was considered statistically significant. Over all differences between groups were determined by one way ANOVA.

\section{RESULTS}

The results presented in table 1revealed that rats treated with paracetamol and ethanol showed significant increases in ALT, AST, ALP activities and total and direct bilirubin levels after 3,4 weeks when compared with control rats. Treatment with allopurinol and garlic showed significant decreases in their levels after 3 and 4 weeks compared with hepatotoxic group. The level of albumin showed significant decrease in rats of group 2 compared with control rats, while there were significant increases in group 3 and 4 compared with hepatotoxicity group (group 2).

The result presented in table 2revealed that rats treated with paracetamol and ethanol showed significant increase in the activities of NO, MDA, TNF and significant decrease in GPx activity after 3 weeks when compared with control rats. In comparison with rats of hepatotoxicity group (group 2), rats protected with allopurinol (group 3) and protected with garlic (group 4) showed significant decrease in MDA, NO and TNF levels and significant increase in GPX activity.

The pathological findings in hepatotoxicity group were severe dilatation and congestion in the central and portal veins associated with ballooning degeneration in the hepatocytes and inflammatory cells 
infiltration in the portal area mainly surrounding the bile ducts (Fig. 2). Protection with allopurinol decrease toxic effects and showed mild degenerative changes as recorded in Fig. 3, while pre-treatment with garlic revealed dilatation in the portal vein as well as few inflammatory cells infiltration while the hepatocytes had moderate vacuolar and hydropic degeneration (Fig.4).

Table (1): Changes of liver function parameters in control, hepatotoxicity, allopurinol protected and garlic protected groups after 3 and 4 weeks duration (mean \pm SE)

\begin{tabular}{|c|c|c|c|c|c|}
\hline Parameters & Period & $\begin{array}{c}\text { G1 } \\
\text { (Control) }\end{array}$ & $\begin{array}{c}\mathrm{G} 2 \\
\text { (Hepatotoxicity) }\end{array}$ & $\begin{array}{c}\text { G3 } \\
\text { (Alloporinol } \\
\text { protected) }\end{array}$ & $\begin{array}{c}\text { G4 } \\
\text { (Garlic } \\
\text { protected) }\end{array}$ \\
\hline \multirow[t]{3}{*}{ ALT (U/L) } & $3 w$ & $58.60 \pm 7.65^{\mathrm{c}}$ & $95.60 \pm 5.04^{\mathrm{a}}$ & $59.20 \pm 4.03^{c}$ & $69.40 \pm 2.32^{b}$ \\
\hline & $4 w$ & $57.40 \pm 9.09^{\mathrm{d}}$ & $102.40 \pm 3.93^{\mathrm{a}}$ & $67.60 \pm 4.71^{\mathrm{c}}$ & $77.00 \pm 3.58^{\mathrm{b}}$ \\
\hline & $3 w$ & $171.80 \pm 5.96^{\mathrm{c}}$ & $235.20 \pm 8.42^{\mathrm{a}}$ & $181.80 \pm 5.88^{\mathrm{bc}}$ & $187.00 \pm 7.44^{b}$ \\
\hline \multirow[t]{2}{*}{ AST (U/L) } & $4 w$ & $161.00 \pm 7.58^{\mathrm{c}}$ & $277.80 \pm 7.17^{\mathrm{a}}$ & $186.20 \pm 4.90^{\mathrm{b}}$ & $190.80 \pm 5.32^{b}$ \\
\hline & $3 w$ & $139.60 \pm 4.08^{c}$ & $213.80 \pm 7.60^{\mathrm{a}}$ & $179.20 \pm 3.56^{\mathrm{b}}$ & $182.00 \pm 3.46^{\mathrm{b}}$ \\
\hline ALP (U/L) & $4 w$ & $151.60 \pm 5.26^{\mathrm{c}}$ & $248.80 \pm 9.74^{\mathrm{a}}$ & $197.80 \pm 6.06^{\mathrm{b}}$ & $199.60 \pm 6.56^{b}$ \\
\hline \multirow[t]{2}{*}{ Albumin (g/dL) } & $3 w$ & $4.16 \pm 0.16^{\mathrm{a}}$ & $2.95 \pm 0.17^{\mathrm{d}}$ & $3.85 \pm 0.17^{b}$ & $3.52 \pm 0.10^{c}$ \\
\hline & $4 w$ & $4.49 \pm 0.16^{\mathrm{a}}$ & $2.58 \pm 0.17^{\mathrm{d}}$ & $3.80 \pm 0.04^{\mathrm{b}}$ & $3.44 \pm 0.07^{\mathrm{c}}$ \\
\hline \multirow{2}{*}{$\begin{array}{l}\text { Total bilirubin } \\
(\mathrm{mg} / \mathrm{dL})\end{array}$} & $3 w$ & $0.52 \pm 0.03^{\mathrm{b}}$ & $0.83 \pm 0.02^{\mathrm{a}}$ & $0.58 \pm 0.02^{\mathrm{b}}$ & $0.53 \pm 0.03^{b}$ \\
\hline & $4 w$ & $0.59 \pm 0.03^{c}$ & $1.23 \pm 0.11^{\mathrm{a}}$ & $0.62 \pm 0.03^{b c}$ & $0.68 \pm 0.02^{b}$ \\
\hline \multirow[t]{2}{*}{$\begin{array}{l}\text { Direct bilirubin } \\
(\mathrm{mg} / \mathrm{dL})\end{array}$} & $3 \mathrm{w}$ & $0.34 \pm 0.02^{\mathrm{b}}$ & $0.44 \pm 0.02^{\mathrm{a}}$ & $0.34 \pm 0.05^{\mathrm{b}}$ & $0.31 \pm 0.01^{b}$ \\
\hline & $4 w$ & $0.39 \pm 0.01^{\mathrm{c}}$ & $0.73 \pm 0.01^{\mathrm{a}}$ & $0.41 \pm 0.03^{\mathrm{c}}$ & $0.45 \pm 0.01^{\mathrm{b}}$ \\
\hline
\end{tabular}

a, b \& c: There is no significant difference $(P>0.05)$ between any two means for the same attribute, within the same row have the same superscript letter.

Table (2): Changes in hepatic MDA,NO,GPX and TNF in control, hepatotoxicity, 
allopurinol protected and garlic protected groups after 3,4 weeks.

\begin{tabular}{cccccc}
\hline & & $\mathrm{G} 1$ & $\mathrm{G} 2$ & $\mathrm{G} 3$ & $\mathrm{G} 4$ \\
Parameters & Period & $($ Control $)$ & $($ Hepatotoxicity) & $\begin{array}{c}\text { (Alloporinol } \\
\text { protected) }\end{array}$ & $\begin{array}{c}\text { (Garlic } \\
\text { protected) }\end{array}$ \\
\hline MDA & $3 \mathrm{w}$ & $245.00 \pm 13.87^{\mathrm{c}}$ & $483.00 \pm 54.88^{\mathrm{a}}$ & $346.33 \pm 51.24^{\mathrm{b}}$ & $340.33 \pm 51.24^{\mathrm{b}}$ \\
$(\mathrm{nmol} / \mathrm{g}$ tissue $)$ & $4 \mathrm{w}$ & $276.67 \pm 4.67^{\mathrm{b}}$ & $777.67 \pm 50.72^{\mathrm{a}}$ & $356.33 \pm 43.06^{\mathrm{b}}$ & $359.33 \pm 34.95^{\mathrm{b}}$ \\
\cline { 2 - 5 } NO & $3 \mathrm{w}$ & $13.67 \pm 0.88^{\mathrm{c}}$ & $25.00 \pm 2.65^{\mathrm{a}}$ & $14.33 \pm 0.88^{\mathrm{bc}}$ & $17.00 \pm 1.15^{\mathrm{b}}$ \\
$(\mathrm{U} / \mathrm{g}$ tissue$)$ & $4 \mathrm{w}$ & $14.00 \pm 0.58^{\mathrm{c}}$ & $29.67 \pm 2.33^{\mathrm{a}}$ & $18.00 \pm 0.58^{\mathrm{b}}$ & $19.33 \pm 1.20^{\mathrm{b}}$ \\
\cline { 2 - 5 } GPX & $3 \mathrm{w}$ & $86.33 \pm 5.81^{\mathrm{a}}$ & $49.00 \pm 3.21^{\mathrm{c}}$ & $76.67 \pm 6.64^{\mathrm{ab}}$ & $72.67 \pm 6.94^{\mathrm{b}}$ \\
$(\mathrm{U} / \mathrm{g}$ tissue$)$ & $4 \mathrm{w}$ & $92.00 \pm 6.24^{\mathrm{a}}$ & $46.33 \pm 2.85^{\mathrm{c}}$ & $74.33 \pm 7.88^{\mathrm{b}}$ & $66.00 \pm 8.50^{\mathrm{b}}$ \\
\cline { 2 - 6 } $\mathrm{TNF}(\mathrm{pg} / \mathrm{ml})$ & $4 \mathrm{w}$ & $14.00 \pm 1.90^{\mathrm{d}}$ & $95.13 \pm 3.62^{\mathrm{a}}$ & $20.97 \pm 4.08^{\mathrm{c}}$ & $36.97 \pm 9.71^{\mathrm{b}}$ \\
\hline
\end{tabular}

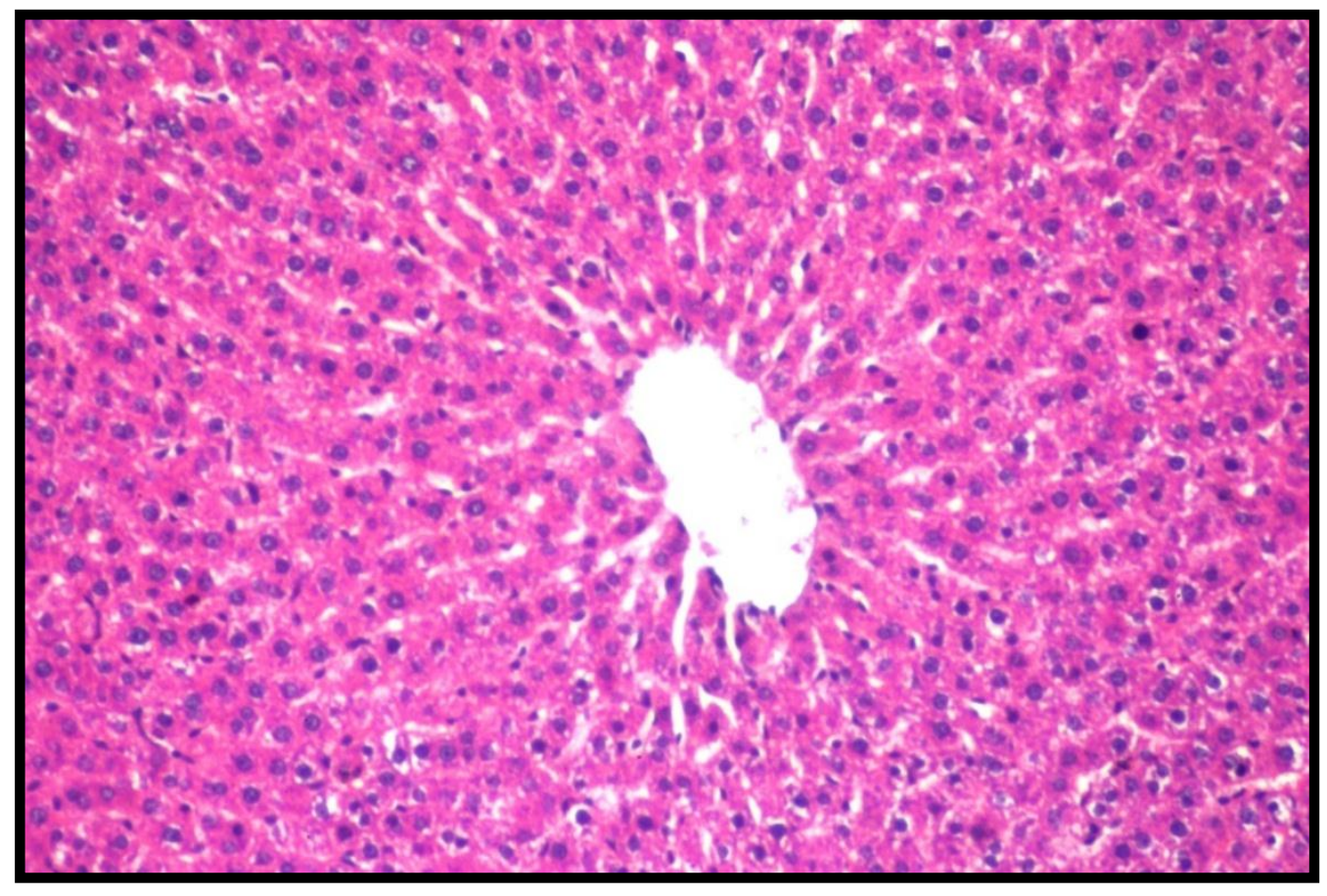

Fig. (1): Liver of rat in control group showed the normal histological structure of the central vein and surrounding hepatocytes in the parenchyma $\mathrm{H} \& \mathrm{E}$ (X40). 


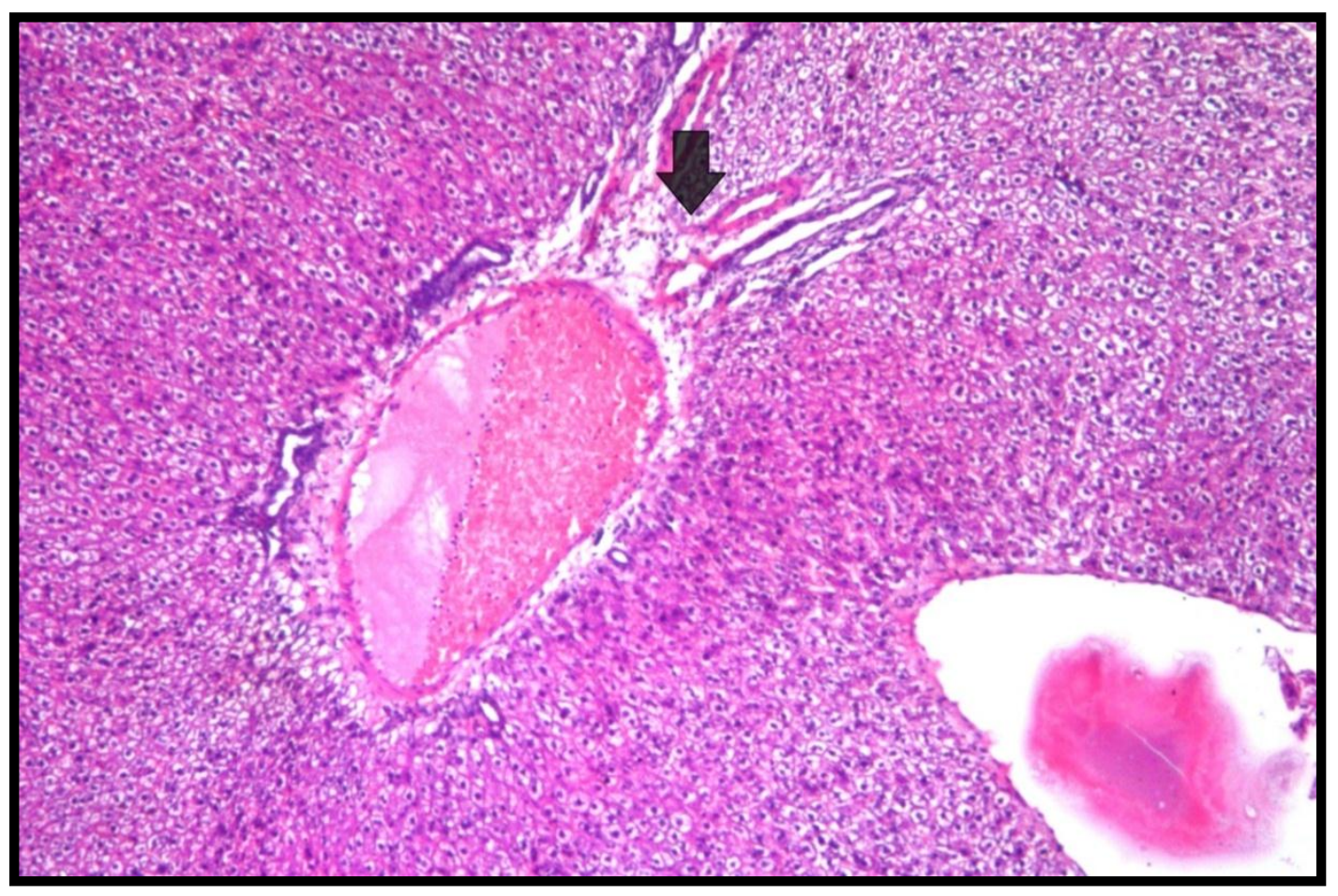

Fig. (2): Liver of rat in hepatotoxicity group showed severe dilatation and congestion in central and portal veins with degeneration in hepatocyte with inflammatory cells infiltration in portal area (arrow) H\&E stain x 16.

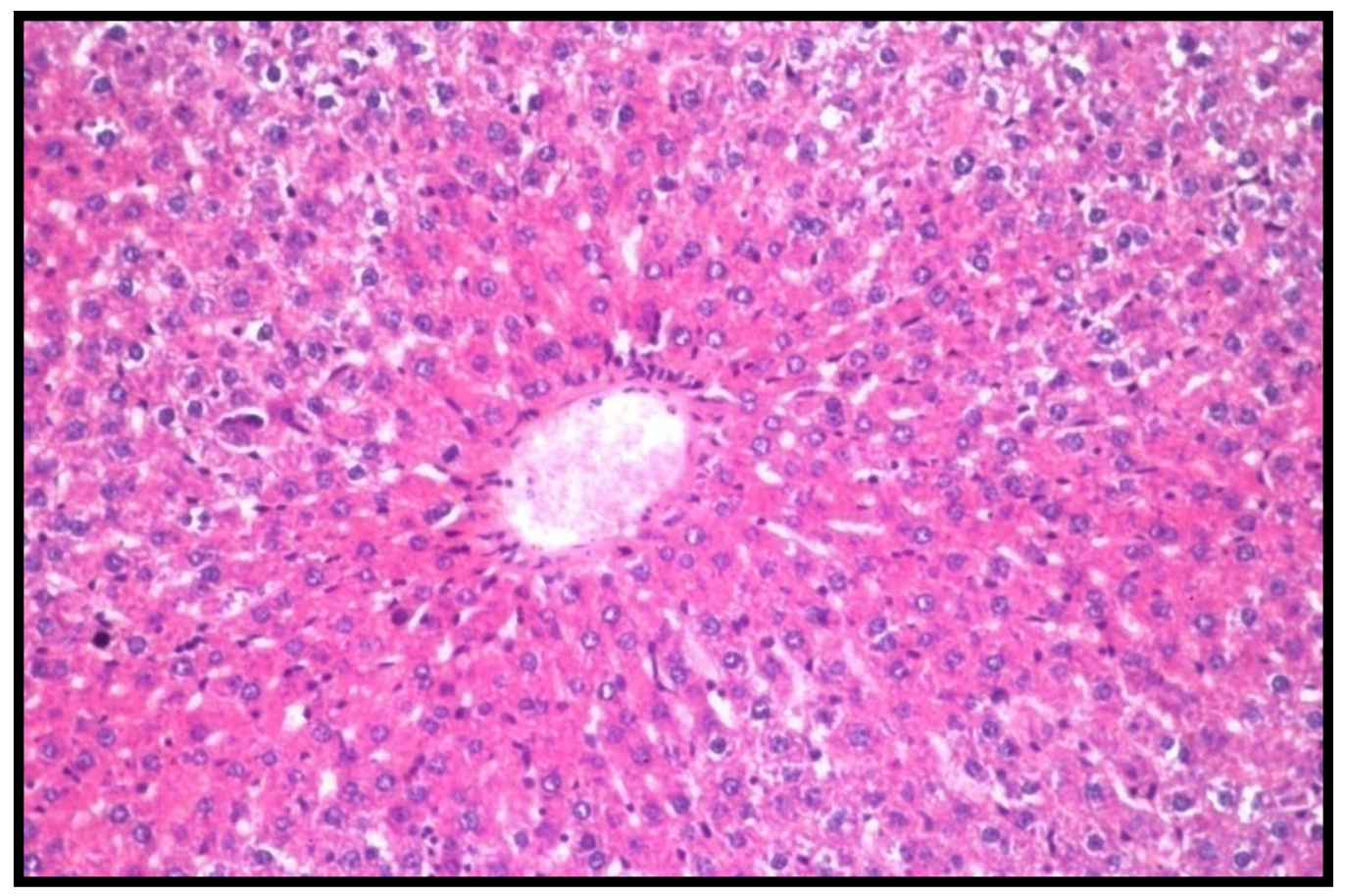


Fig. (3): Liver of rat in allopurinol protected group showing mild vacuolization of the hepatocyte H\&E stain $x 40$.

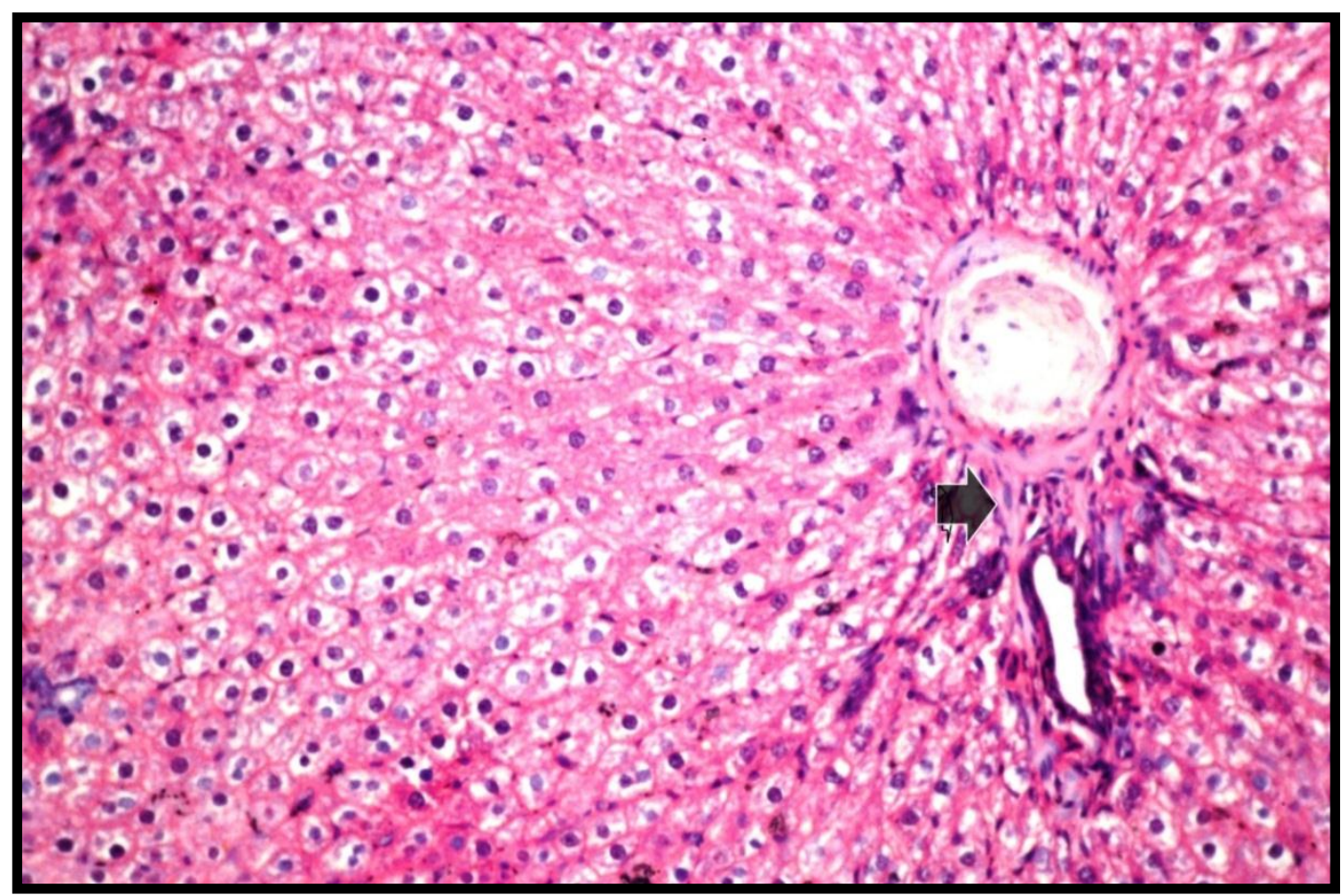

Fig. (4): Liver of rat in garlic protected group showed dilatation of portal vein with moderate vacuolar and hydropic degeneration (arrow)H \& E stain x 40 .

\section{DISCUSSION}

In the present study our data showed that administration of paracetamol plus ethanol in rats, caused hepatocellular disturbance indicated by significant increases in ALT, AST and ALP activities in third and fourth weeks when compared with control rats . Our results agree with Bhadauria and Nirala (2009). The elevated activities of serum AST, ALT and ALP are indicative of cellular leakage and loss of functional integrity of cell membrane in liver (Premila, 2005). Due to liver injury the transport function of the hepatocytes gets disturbed, resulting in the leakage of plasma membrane (Rang et al., 2003).On the other hand, allopurinol protected group improve liver parameters and decrease hepatocellular disturbance induced by acetaminophen and ethanol that indicated by significant decreases in levels of ALT, AST and ALP after third and fourth weeks compared with group 2. Our results agree with Nesreen et al., (2015). Allopurinol is a xanthine oxidase inhibitor, and its active metabolite, oxypurinol, provided protection against hepatic injury by suppressing the production of ROS (Karwinski et al ., 1994)..Moreover garlic protected group showed significant decrease in ALT, AST and ALP in second and third collection. Our result agree with Padalko et al. (2012), The reduction of the liver enzymes in rats 
protected with garlic may be due to its antioxidant effect that reduces the free radical-induced oxidative damage in the liver, thereby stabilizing the membrane permeability and reducing the leakage of enzymes into the blood (Salman et al., 1999).

Administration of acetaminophen plus ethanol in rats caused increase in bilirubin (total, direct and indirect) and decrease of albumin concentration in third and fourth weeks. Our results agree with Wang et al., (2008). The increase in total bilirubin level in the serum could be attributed to the increase in the rate of red blood corpuscles destruction and damage of liver tissue (Hall et al., 2001). Serum albumin of rats were significantly decreased may be attributed to significant fall in protein synthesis (Kanchana and Sadiq, 2011), which could be due to the peroxidative damage of liver as albumin is produced by liver (Bharathi et al., 2011).On contrast, allopurinol protected group showed significant decrease in bilirubin (total, direct and indirect) and increase of albumin in third and fourth weeks compared with hepatotoxicity group. Our result agree with Aldaba-Muruato et al., (2013) who reported that allopurinol prevent liver injury by inhibition of free radical formation so prevent elevation of bilirubin (AldabaMuruato et al., 2013).Moreover, garlic protected group showed a significant decrease in bilirubin (total, direct and indirect) and increase of albumin in third and fourth weeks. Our result agree with Arthur et al ., (2003) who reported that, Garlic limiting the production of NAPQI production so minimize the toxic effects of acetaminophen overdose.

The biochemical results confirmed by histopathological changes in liver which showed severe dilatation and congestion in the central and portal veins associated with ballooning degeneration in the hepatocytes as well as fibrosis and inflammatory cells infiltration in the portal area mainly surrounding the bile ducts in group 2 in fourth weeks. that are in accordance with (Ibrahim et al., 2011).While, in allopurinol group showed mild degenerative changes. This agree with Stephanie et al., (2010) .Also the biochemical results confirmed to histopathological changes in liver of rats in garlic group which showed dilution in portal area in fourth week this agree with Salman et al., (1999)

Referring to antioxidant and antiinflammatory parameters, results showed significant increases in MDA, NO and TNF$\alpha$ and significant decrease in GPX in hepatotoxicity group in third and fourth weeks. These results are in agreement with Chen et al., (2012). The toxicity of acetaminophen develops when its dose exceeds safe hepatic detoxification pathways (Eesha et al., 2011) where the reactive metabolite N-acetyl-pbenzoquinone mine (NAPQI) is formed in a rate that depletes cellular GSH faster than its re-synthesis. Semi Quinone radicals, can then covalently bind to the macromolecules of cellular membrane and increase the lipid peroxidation and MDA production resulting in massive tissue damage. The damaged hepatocytes trigger a cascade of inflammatory responses leading to various degrees of liver damage which is further propagated by the migration of different extra hepatic inflammatory cells to the area of injury (Chen et al., 2012).

The Elevated oxidative stress caused the release of pro-inflammatory mediators such as NO via inducible nitric oxide synthase in APAP intoxicated liver which results in cellular dysfunction (Ahmad et al., 2012). APAP caused significant activation of NF- $\kappa \mathrm{B}$, caused the release of pro-inflammatory mediators TNF- $\alpha$ and IL$1 \beta$ and elevate oxidative stress (Al-Belooshi 
et al., 2010). AS for the effect of allopurinol on antioxidant and anti-inflammatory parameters, there was significant decrease in MDA, NO and TNF- $\alpha$ and significant increase in GPX in third and fourth weeks. This result agree with AlMaruf et al.,(2014). Allopurinol was reported to have immunomodulatory properties evidenced as suppression of nuclear expression of nuclear factor kappa Beta (NF-kB) as well as attenuation of the expression of inflammatory adhesion molecules (Muir et al., 2008, Aldaba-Muruato et al., 2013).

Moreover, garlic protected group showed significant decrease in MDA, NO and TNF- $\alpha$ and significant increase in GPX in third and fourth weeks. These results agree with Capasso et al., (2013) AGE exhibited a protective effect against acetaminophen through its powerful antioxidant and freeradical scavengers (Abdel-Halim and Mohamed, 2012). The anti-oxidant potential of garlic and have suggested that garlic attenuates ROS by increasing endogenous anti-oxidant. Garlic contains several organ sulfur compounds such as allicin, diallyl sulfide, and diallyl disulfide which are valuable precursors for glutathione biosynthesis. (Wei et al.,2001)

It is concluded that allopurinol and garlic extract are effective products for improving liver functions and preventing damage and oxidative stress induced by acetaminophen and ethanol.

\section{REFERRENCES}

Abd El-Halim S.S. and Mohamed M.M. (2012): Garlic powder attenuates acrylamide-induced oxidative damage in multiple organs in rat. $\mathbf{J}$ ApplSci Res 8:168-173.

Ahmad S.T., Arjumand W., Nafees S., Seth A ., Ali N., Rashid S., SultanA.S.(2012 ): Hesperidin alleviates acetaminophen induced toxicity in Wistar rats by abrogation of oxidative stress, apoptosis and inflammation. ToxicolLett. 208:149-161.

Al Maruf A., Wan L. and O'Brien P.J. (2014): Evaluation of azathioprineinduced cytotoxicity in an in vitro rat hepatocyte system. Biomed. Res. Int.; 2014 : 379748.

Al-Belooshi T., John A., Al - Otaiba A. and Raza H. (2010): Acetaminopheninduced mitochondrial oxidative stress in murine J774. 2 monocyte macrophages. Am J Biomed Sci. 2:142-154.

Aldaba-Muruato L.R., Moreno M.G., Shibayama M., Tsutsumi V. and Muriel P.(2011): Protective effects of allopurinol against acute liver damage and cirrhosis induced by carbon tetrachloride: modulation of NF- $\kappa \mathrm{B}$, cytokine production and oxidative stress. J. Epub 1820(2):6575.

Arthur JR, McKenzie RC, Beckett GJ. Selenium in the immune system. J Nutr2003;133:1457S-1459S.

Basim Anwar Shehata Messiha, Amira M Abo-Youssef (2015): Protective effects of fish oil, allopurinol, and verapamil on hepatic ischemiareperfusion injury in rats Department of Pharmacology, Faculty of Pharmacy, BeniSueif University, BeniSueif, Egypt, 6 (2) : 351-355.

Bharathi P., Reddy A.G., Reddy A.R. and AlpharaM .(2011): A study of certain herbs against chlorpyrifosinduced changes in lipid and protein profile in poultry. Toxicol. Int. 18: 44-46. 
Hepatoprotective effect of allopurinol and garlic extract against experimentally - induced hepatotoxicity

Burtis C.A., Ashwood E.R. and Brunss D.E. (2012): Tietz textbook of clinical chemistry and molecular diagnostic Elsevier health science

Capasso A. (2013): Antioxidant action and therapeutic efficacy of Allium sativum Molecules, 18 (1): 690700.

Chen P.J., Pang V.F., Jeng Y.M, Chen T.J., $\mathrm{Hu} \quad$ F.C., Chi W.T., . (2012): Establishment of a Standardized Animal Model of Hepatotoxicity Using-paracetamol induced Hepatotoxicity. Journal of Food And Drug Analysis Volume: 20Issue: 1Pages: 41-47

Published: MAR 2012.

Douma B.T., Watson W.A. and Biggs H.G. (1972): Albumin standard and measurement of serum albumin with bromocresol green clinchimaceta, 31(1):87-96.

Dugan JE, Gius D and Wink DA(2005)., oxidative stress and herpal roles Human ExpToxicol. 2005;21;77-81

El-KhishinIman A., Yara Mohamed Medhat El-Fakharany, and Omaima I. Abdel Hamid (2015): Role of garlic extract and silymarin compared to dimercaptosuccinic acid (DMSA) in treatment of lead induced nephropathy in adult male albino rats oxicol Rep. 2015; 2: 824-832.

Eidi A., Eidi M. and Esmaeili E. (2006):Antidiabetic effect of garlic (Allium sativum L.) in normal and streptozotocin-induced diabetic rats. Phytomedicine. $2006 \quad$ Nov;13(910):624-9. Epub 2005 Nov 2.

Esha M.E., Arikpo G.E., Enyi-Idoh K.H. and Ikpeme E.M. (2011): An evaluation of the antimicrobial synergy of Garlic (Allium sativum) and Utazi
(Gongronemalatifolium) on Escherichia coli and Staphylococcus aureus. Malaysian Journal of Microbiology, 7: 49-53.

Hall J.E. (2001): The promise of translational physiology. Am. J. Physiol. Gastrointest. Liver Physiol. 281: G1127-G1128.

Hinson Jack A. , Dean W. Roberts and Laura P. James (2010): Mechanisms of Acetaminophen-Induced Liver Necrosis HandbExpPharmacol.; (196): 369-405.

Ibrahim M., Khaja Z.U. and NarasuM.L. (2011): Hepatoprotective activity of Boswellia serrata extracts: in vitro and in vivo studies Int $\mathbf{J}$ Pharm Appl, 2, pp. 89-98.

Kanchana N. and Sadiq A.M. (2011): Hepatoprotective effect of Plumbagozeylanicaon paracetamol induced liver toxicity in rats. Int. J.

Pharm. Pharm. Sci. 3(1): 151-154

Karwinski W., Bolann B., Ulvik R., Farstad M., Soreide O. (1994): Normothermic liver ischemia in rats: xanthine oxidase is not the main source of oxygen free radicals Res. Exp. Med., 193, pp. 275-283.

Kei S. (1978): Serum lipid peroxide in cerebrovascular disorder determination by anew coloimetric method clinicachimicaaceta 90, 3743.

Laurie F. Prescott (2016):Paracetamol, alcohol and the liver. $\mathrm{Br} \mathrm{J}$ ClinPharmacol.; 49(4): 291-301.

Montgomery, H. A. C. and Dymock, J .F. (1961): Colorimetric determination of nitric oxide. Analyst., 86:414417. 
Muir S.W., Harrow C., Dawson J., Lees K.R., Weir C.J., Sattar N., Walters M.R.(2008): Allopurinol use yields potentially beneficial effects on inflammatory indices in those with recent ischemic stroke: a randomized, double-blind, placebo-controlled trial. Stroke.;39:3303-3307

Nesreen E.M. Mohammed, Basim A.S. Messiha, Ali A. Abo-Saif (2015): Effect of amlodipine, lisinopril and allopurinol on acetaminophen-induced

hepatotoxicity in rats (2015) Saudi Pharmaceutical Journal.

Ohkawa H., Ohishi N. and Yagi K. (1979):Assay for lipid peroxidase in animal tissue by thiobarbituric acid reaction analytical biochemistry 95 , 351-358.

Padalko V., Kozlova E. and Leonova I. (2012): Protective efficacy of garlic on cadmium induced oxidative stress in young and adult rats Oxid. Antioxid. Med. Sci., 1 (2), pp. 101-109.

Paglia D.E. and Valentine W.N. (1967): Studies on the quantitative and qualitative characterization of erythrocyte glutathione peroxidase. The Journal of Laboratory and Clinical Medicine 70, 158-169.

Premila A. (2005): Oxidative stress in paracetamol induced pathogenesis: (I) Renal damage. Indian J. Biochem.Biophy.42: 59- 62.

Rang H.P., Dale M.M., Ritter J.M., Moore P. (2000): Pharmacology 2003 Churchill Livingstone: London; 6th edn.Br J Pharmacol. 2000;129:110114.

Reitmain S. and Frankkel S. (1957): A colorimetric method for determination of AST and ALT AM.J.clin.path.25:56.
Salman H., Bergman M., Bessler H., Punsky I. and Djaldetti M. (1999): Effect of garlic derivative (alliin) on peripheral blood cell immune responses. Int $\mathbf{J}$ Immunopharmacol; 21: 589-597.

Stephanie Peglow, Alexander H. Toledo (2011): Allopurinol and xanthine oxidase inhibition in liver ischemia reperfusion Volume 18, Issue 2March 2011 Pages 137-146 Journal of Hepato-BiliaryPancreatic Sciences.

Tiez N.W., Burtis C.A, Duncan P. and Ervin K. (1983):Reference method for measurement of alkaline phosphatase activity in human serum Journal of clinical chemistry 29 (5): 751-761.

Visentainer J.E., Lieber S.R., Persoil L.B, Vigorito A.C., Aranha F.J. and BritoEid K.A. (2003): and acute graft-versus host disease after HLA- identical hematopoietic stem cell transplantation. Exp Hemat. Stem Cell 31(11):10441050.

Wang L., Cheng D., Wang H., Di L., Zhou X., Xu T., et al.(2009): The hepatoprotective and antifibrotic effects of Saururuschinensis against carbon tetrachloride induced hepatic fibrosis in rats. J Ethnopharmacol; 126:487-91.

WarisG ;Haseebahsan and Alam K (2006) Reactive oxygen spp development in chronic condition Journal of carcinogenesis;45:33-45

Wei Z, Lau BHS. Garlic inhibits free radical generation and augments antioxidant enzyme activity in vascular endothelial cells. Nutr Res 1998;18:61-70.. McKenzie

Yuan H.D., Jin G.Z. and Piao G.C. (2010): Hepatoprotective effects of an active part from Artemisia sacrorumL. edeb against acetaminophen- induced toxicity in mice. J. Ethnopharmacol. 127: 528-533. 